\title{
Análisis georreferenciado sobre jóvenes infractores de ley de la comuna de Puente Alto, Santiago de Chile
}

Gabriel Sepúlveda. Universidad de las Américas, Santiago, Chile.

Leonardo Sepúlveda. Universidad Politécnica de Catalunya, Barcelona, España.

RESUMEN | A partir de reconocer los efectos indeseados de una política habitacional regida por la maximización de la cobertura implementada en las últimas décadas en Chile, y desde una perspectiva crítica respecto al uso de una georreferenciación estigmatizadora y meramente situacional aplicada a problemáticas delictuales, se propone un uso alternativo de estas técnicas. El objetivo es precisar la concentración sectorial de jóvenes que han infringido la ley tanto para favorecer la discusión en torno a medidas y sanciones en materia de justicia juvenil, como para orientar acciones correctivas a nivel de políticas habitacionales y urbanización, las que deberían inspirarse en la consagración de un verdadero derecho a la ciudad.

PALABRAS CLAVE | política habitacional, marginalidad, seguridad ciudadana.

ABSTRACT | Based on the recognition of the impacts of a quantitative rather than qualitative focus on social housing policy (in recent decades in Chile) and from a critical perspective regarding the use of a stigmatizing and situational georeferencing of criminal problematics, an alternative use of these techniques is proposed in this article. The aim is to specify the sectoral concentration of young people who have violated the law, in order to promote more discussion on a better execution of measures and sanctions in juvenile justice, as well as to guide corrective actions at the level of housing policies and urbanization, which should be inspired by the entrenchment of a true "right to the city".

KEYWORDs | housing policy, marginality, citizen security.

Recibido el 4 de junio de 2019, aprobado el 13 de agosto de 2019.

E-mails: G. Sepúlveda, gsepulvedan@udla.cl | L. Sepúlveda, leonardo.sepulveda.navarro@upc.edu 


\section{Introducción}

La presente entrega propone que el uso de metodologías de georreferenciación destinadas a visualizar formas de concentración de los domicilios de jóvenes que han infringido la ley puede ser relevante, en la medida en que permitiría hacer evidentes algunos impactos de políticas habitacionales aplicadas en el pasado. Ello, a su vez, podría orientar el desarrollo de las sanciones penales en el medio libre (de forma oportuna considerando la intervención comunitaria), así como abrir nuevas líneas de investigación, mientras se mantengan algunos resguardos descritos brevemente en la discusión final.

Ciertos autores resaltan la necesidad de contar con mayor cantidad de estudios sobre movimientos de pobladores o respecto de las consecuencias de las erradicaciones de tomas irregulares de terrenos (Del Romero, 2018, p. 48). También señalan la necesidad de investigaciones sobre segregación residencial (Arriagada \& Rodríguez, 2003; Sierralta, 2008) o sobre la relación violencia-ciudad (Carrión, 2008, p. 112), entre otros temas relevantes a la hora de comprender fenómenos de exclusión y vulnerabilidad generados a partir de procesos urbanos.

Diversas fuentes aseguran que las políticas habitacionales en el Chile de las últimas décadas han tenido cierto éxito y reconocimiento. Por mencionar algunos progresos concretos (Ducci, 1997), cabe señalar la fuerte disminución en la ocupación ilegal de terrenos hasta fines del siglo $\mathrm{xx}$ y la implementación de servicios básicos a casi la totalidad de la población, que frenan ostensiblemente problemáticas como la desnutrición y enfermedades infecciosas. Además, se plantea que estas políticas han tendido a beneficiar efectivamente a los sectores más desposeídos, en plazos no demasiado extensos y en condiciones de ahorro mínimo.

No obstante, las políticas subsidiarias implementadas en el país se han desarrollado a través de estrategias de localización basadas en modelos de crecimiento urbano extensivo y en áreas periféricas de la ciudad, priorizando como criterio el bajo valor de suelo. Estas nuevas áreas habitacionales se han planificado sin la necesaria integración funcional con las zonas urbanas consolidadas, circunstancia que, unida al marcado déficit y precariedad del equipamiento complementario de salud, educación, áreas verdes y seguridad, ha generado en estos extensos paños graves problemas de segregación residencial. En una concepción amplia, se entiende esta como la aglomeración geográfica de familias de una misma condición social, que se expresa tanto en la tendencia de un grupo a concentrarse en algunas áreas de la ciudad, como en la conformación de áreas socialmente homogéneas y la vivencia de segregación o exclusión (Sabatini, 2001).

La precariedad de los equipamientos en materia de salud, educación, áreas verdes y seguridad ha tendido a desvalorizar objetiva y subjetivamente los entornos de la periferia urbana señalados. Inciden en tal situación factores como el reducido tamaño de los terrenos, que dificulta una buena calidad de vida; las estrechas dimensiones de las viviendas, que impiden el desarrollo de las familias; y el hacinamiento junto con el menoscabo de la privacidad, al no ser viviendas aptas para ampliaciones o mejoras. Todo ello se combina con la destrucción de lazos vecinales y familiares y la pérdida de las redes basadas en la reciprocidad y confianza, afectando el sentido 
de pertenencia y aumentando el desinterés por participar en una conservación, cohesión y organización del territorio. Tal proceso fue observable en ocupaciones irregulares de terreno, donde la organización terminaba reducida a condición de posibilidad para la obtención de beneficios habitacionales.

Problemas adicionales habitualmente descritos en la población relocalizada en sectores con alta densidad de vivienda social, pero sin acceso a servicios y transporte, redundan en una alta morosidad en los pagos de las viviendas y servicios, dificultades en el acceso a empleo, aumento de problemáticas de salud física y mental, la merma en niveles educacionales de la población, entre una diversidad amplísima de desmedros. Es esta una situación concomitante con el incremento de la violencia e inseguridad, factores que, como señala Ducci (1997), "han pasado a ser características de los barrios de los más pobres”, con lo que finalmente la ciudad que la política habitacional genera para los más pobres "está produciendo la destrucción y pérdida de componentes sociales fundamentales, algunos de los cuales podrían ser recuperados si se entendieran los procesos y las dinámicas subyacentes” (p. 113).

En suma, se trata de procesos que tienen como resultado la conformación de sectores donde se agrupan desventajas de todo tipo. Tal como propone Gonzalo Saraví (2004), conviene superar la visión binaria pobre/no pobre "para asumir una más dinámica y procesal", destacándose "el rol del espacio público como potenciador de procesos de acumulación de ventajas y desventajas en comunidades urbanas pobres" (p. 34). Se trata esencialmente de acumulación dinámica, donde residir en estas áreas de la ciudad, junto con ser niño o adolescente y que además ha nacido en el marco de la erradicación/extrañamiento, son hechos que configuran una situación diferente de la vivida por sus mayores, quienes debieron articular la erradicación sobre una identidad ya conformada. De ahí un efecto multiplicador de rasgos objeto de exclusión en jóvenes habitantes de estos sectores.

La falta de una organización comunitaria solidaria en busca del sueño de la casa propia ha encontrado la desarticulación de pesadilla que acarrea una situación periférica y de extrañamiento como la que acontece una vez lograda la reubicación habitacional. Vale la pena diversificar y abundar en una examinación minuciosa de las consecuencias de estos quiebres urbanos y cómo ellos se expresan a nivel territorial y social a la vez que subjetivo, impactando de vuelta a la sociedad $-\mathrm{y}$ con similar violencia- mediante el delito.

\section{Erradicaciones y consecuencias de las políticas de "solución habitacional”}

Desde el modelo de erradicaciones propio de las dictaduras latinoamericanas (Arriagada \& Rodríguez, 2003, p. 36), las soluciones habitacionales desembocaron con claridad en una segregación residencial profunda y consolidada, donde la aglomeración geográfica de familias empobrecidas ha producido una forma de homogeneidad negativa y configurado vivencias de segregación y exclusión, sin que sea posible avizorar una verdadera construcción de comunidad.

La erradicación de campamentos en Santiago de Chile adoptó cierta mecánica desde la dictadura militar hasta los gobiernos democráticos, a través de la cual directamente se desplazó a los pobladores a comunas periféricas, con déficits de 
equipamiento y niveles de pobreza evidentes. A lo anterior se añade, según señalan Álvarez y Cavieres (2016), que "la heterogeneidad del origen socioterritorial de sus habitantes, sin historia ni identidad compartida, y la localización segmentada respecto de las fuentes laborales y de los servicios, llevó a que hasta el día de hoy, estos territorios hayan tenido grandes dificultades en dotarse de indicadores urbanos compatibles con estándares mínimos de calidad de vida” (p. 160). Todo ello en un contexto de crecimiento demográfico explosivo de algunas zonas periféricas de la capital, proceso del cual es un buen ejemplo la comuna de Puente Alto, cuyos índices de crecimiento poblacional y de criminalidad se han desarrollado a la par (Figura 1).

Figura I | Número de habitantes en la comuna de Puente Alto. Censos de Población (1875 a 2016)

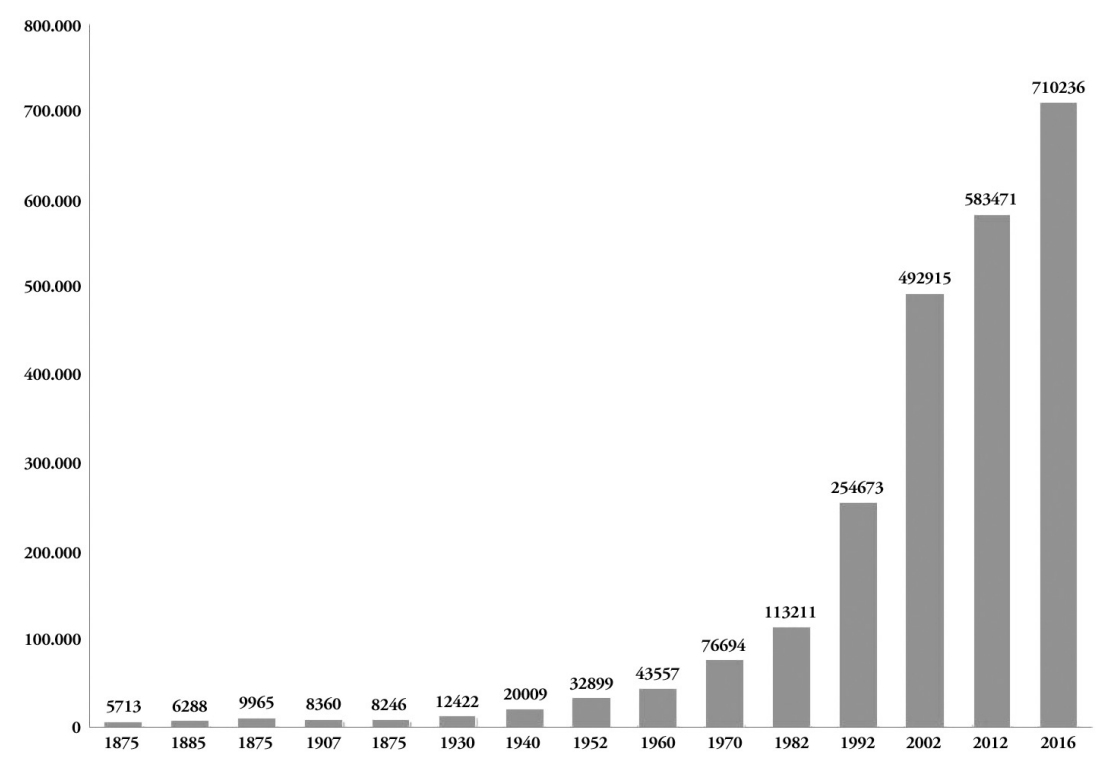

FUENTE: MUNICIPALIDAD DE PUENTE ALTO

Las anteriores dinámicas de relación comunitaria entre pobladores se desvanecieron rápidamente una vez desaparecido el lazo de confianza y propósito colectivo que los unía en los campamentos, "puesto que los pobladores ya no se reconocían como parte de un conjunto social con historia común y cierta homogeneidad, en la medida en que fueron sometidos a aceptar una convivencia con gente de distinta procedencia" (Álvarez \& Cavieres, 2016, p. 160). Esto no es negativo en sí mismo; más bien, la falta de cohesión en la mezcla de distintas formas de precariedad es lo que finalmente asentó la exclusión en estos barrios, desde el principio desunidos. La posesión de una vivienda consiguió que los pobladores perdieran beneficios sociales concedidos en el marco de la ocupación de terrenos, afrontando súbitamente el 
deber de solventar deudas y cuentas regulares por los servicios a los que habían accedido, en situación de lejanía e inaccesibilidad a fuentes de trabajo y centros urbanos, tarea que ha resultado extremadamente demandante o simplemente imposible de cumplir para muchos.

Luego, una vez asegurada la cobertura en posesión de vivienda, quedaron desatendidas las problemáticas consecuentes respecto a fenónemos sociales de desarraigo, estigmatización, aislamiento y guetización, que luego se vieron reforzados por políticas de seguridad ciudadana que no tienden a la integración social o a una comprensión más allá de la mera vigilancia de lo situacional.

El efecto es global para la ciudad: "la segregación adquiere especial importancia, debido a que el territorio de las grandes ciudades está siendo organizado bajo una estricta lógica de segregación de grupos socio-económicos que se caracteriza por distanciamiento social, agudizada desigualdad y erosión de la cohesión social" (Arriagada \& Morales, 2006, p. 46). De este modo, no ser parte de un ambiente socialmente diverso disminuye con claridad la calidad de vida de las personas, "así como también aumenta la frustración, desesperanza e insatisfacción de los residentes de estos territorios" (Manzano, 2009).

\section{Violencia y jóvenes urbano-populares}

Apenas concretadas las erradicaciones, comenzaron a observarse las señales del desarraigo. Los sectores afectados por estas probemáticas cayeron paulatinamente en una forma específica de "desorganización social", entendida como el proceso donde no pueden seguir haciendo efectivos los valores que personas y colectivos traían desde su vida anterior, sobre todo en el marco de las organizaciones de pobladores. Se trata de una situación que posteriormente se conforma como la inhabilidad de la comunidad para continuar sustentando "redes de conocimiento mutuo y amistad", así como "para supervisar y orientar la conducta de nińos y jóvenes" a través de un control social informal (Manzano, 2009, p. 136), aspectos que van dando pie a niveles de tensión en aumento. Las nuevas obligaciones que asumieron los adultos los mantienen gran parte del día en sus lugares de trabajo y en el transporte público, con lo que vastos sectores periféricos se fueron convirtiendo en "poblaciones dormitorio", donde son los niños y jóvenes los que han quedado sin compañía e incluso, en muchos casos, enclaustrados en los domicilios.

Paralelamente, una segmentación urbana y domiciliaria estricta ha terminado por conformar barrios escépticos sobre la movilidad por vías prosociales, "disminuyendo la capacidad de los jóvenes para generar ingresos laborales" (Arriagada \& Rodríguez, 2003, p. 56), lo que repercute en las expectativas que se forman los adolescentes sobre su futuro (Manzano, 2009, p. 65) y terminan por configurar una "cultura del gheto [sic], en la que el relato común (la intersubjetividad barrial) es el de la desesperanza en sí mismo, en el colectivo y en la sociedad" (Sierralta, 2008, p. 31). La situación de la niñez y juventud habitante de estos territorios va revelando así un segmento de la población donde recrudece la mencionada acumulación de desventajas, las que van alterando las dinámicas de identificación y uso del contexto 
colectivo, con lo que resulta característico el fenómeno juvenil de apropiación diferenciada del espacio público en sectores marginados.

Como consecuencia de lo anterior, mientras que en otros estratos socioculturales la vía pública solo importa en tanto lugar de tránsito, "la calle representa para los jóvenes de sectores populares no solo un espacio público más importante que para otros sectores sociales, sino el más importante como espacio de encuentro y sociabilidad" y aparece como "único espacio accesible, disponible para la conquista" (Saraví, 2004, p. 41). En un escenario social y vital donde reinan en los jóvenes la incertidumbre, la frustración, la crisis de autoestima y de identidad, muchos de ellos consolidan las calles de sus barrios como lugar de normas, valores e historia propios, donde vehiculizan una nueva identidad y un prestigio inusitado desde su capacidad de infundir temor y dominar el espacio público: "respeto ganado" que, pese a ser negativo, los convoca. De este modo, y "con el control del espacio público local, los jóvenes responden construyendo un espacio interior de integración que, paradójicamente, será percibido por el exterior como fuente de amenaza" (Saraví, 2004, p. 43).

Diversos estudios indican una potente correlación entre la segregación residencial de estos sectores y una alta tasa de inactividad juvenil general en hombres y mujeres (Sierralta, 2008). Asimismo, existen investigaciones que afirman que los barrios asociados a las tasas más altas de crecimiento demográfico son los que tienen los niveles más altos de delincuencia (Arriagada \& Rodríguez, 2003). En ellos, ciertas modalidades de uso del suelo y segregación residencial tienen importancia significativa en la producción de ciertos tipos de violencia (Carrión, 2008), siendo la dimensión de "homogeneidad/heterogeneidad, vital para el devenir de las vidas de los niños y jóvenes pobres que habitan barrios segregados" (Sierralta, 2008, p. 27). El círculo inseguridad/violencia entra en escalada, toda vez que "la percepción de inseguridad refuerza la ruptura de los vínculos sociales, debilita el tejido social e incrementa la desconfianza interpersonal en estos vecindarios, procesos que a su vez favorecen la criminalidad" (Lunecke, 2016, p. 110).

Otras dinámicas vecinales fortalecidas por estas intervenciones habitacionales son de compleja detección, pero de consecuencias profundas. Los vecinos más prosociales, es decir, quienes suelen respetar normas y leyes, persisten en hallar vías de movilidad social cambiando de barrio. Sus casas quedan disponibles para el arriendo de allegados o cercanos de quienes queden en el lugar, nuevos residentes que se identifican con la dinámica violenta del vecindario. Junto con aumentar su concentración, generan focos conflictivos en los que la superioridad numérica les permite desencadenar escaladas de violencia por el control de las zonas. En otras ocasiones, al emigrar de forma menos planificada, los prosociales (es decir, justamente los más enclaustrados en sus hogares y más intimidados por el espacio compartido en el marco barrial) dejan transitoriamente vacantes sus domicilios, los que en corto tiempo son ocupados ilícitamente por vecinos o parientes de quienes siguen concentrándose densamente en sectores cada vez más contraculturales. Subsecuentemente y para optimizar estos fines, modifican las viviendas, uniendo terrenos internamente y, en el caso del crimen organizado, incluso concretando túneles que unen los terrenos, lo que garantiza el ocultamiento de actividades (por 
muchas cámaras o drones que sobrevuelen algunas áreas), así como la evasión ante redadas y operativos policiales en general.

Procesos como los mencionados se dan de manera lenta y casi imperceptible, pero con efectos acumulativos notorios en la conformación cada vez más contrastante entre sectores prosociales versus barrios contraculturales (o sea, los que cuentan con una mayor proporcion de miembros implicados en dinámicas delictuales y de constante oposición a formas de autoridad convencionales), lo que va logrando un efecto recursivo. Ocasionalmente, el círculo vicioso se acelera de manera intencionada, toda vez que algunos habitantes hostilizan o recurren a conflictos artificiales a fin de expulsar a vecinos prosociales y dar cabida a amigos o familiares lejanos que sostengan prácticas similares a las propias, o simplemente con el fin de aliviar el hacinamiento en sus viviendas, integrando a cada vez más personas en cada hogar. Este fenómeno de activa selección y filtros internos en la configuración de los barrios resulta muy significativo y requiere un examen más dinámico, constituyendo un problema fuertemente subanalizado y en el que los adolescentes y jóvenes tienen un activo protagonismo.

Es de especial importancia, entonces, un análisis minucioso de los procesos de erradicación y posterior exclusión de una proporción considerable de la población a través de soluciones que acarrean segregación residencial, la cual constituye un "ambiente que favorece una elevada tolerancia o indiferencia a la desigualdad entre las clases acomodadas y medias, y una lenta pero creciente adhesión a la delincuencia entre ciertos grupos de los barrios y zonas excluidas del progreso" (Arriagada \& Morales, 2006, p. 47). De este modo, se van conformando barrios donde la violencia permanece, se instala "en las relaciones cotidianas, al interior de los hogares, en espacios públicos y comunitarios” (Manzano, 2009, p. 86).

En suma, quizá convenga visualizar la problemática de la violencia, según señala Carrión (2008), como una "relación particular del conflicto social, y por lo tanto como una compleja construcción social y política que se cristaliza en un territorio y en un tiempo específico", a fin de dilucidar cómo atańen estos procesos a la noción misma de seguridad, más que relegar el fenómeno de la violencia urbana a causalidades biológicas o morales, o simplemente a ser considerado un "factor de riesgo" (p. 115). Cabe precisar en este contexto las dimensiones del concepto de seguridad pública, el cual se puede especificar en tres tipologías respecto a su ámbito y carácter: seguridad social, seguridad ciudadana y seguridad urbana.

La seguridad social se entiende como un derecho humano garantizado por la Constitución Política de Chile en su artículo 19, no 18 , el que operativamente se constituye como un instrumento de justicia social que se expresa en un conjunto de leyes, políticas y medidas de protección social respecto a garantizar el acceso a "prestaciones básicas", referidas al desempleo, salud, maternidad, invalidez, entre otros.

En el caso del concepto de seguridad ciudadana, este refiere más bien a la misión del Estado en cuanto a "procurar la existencia de las condiciones necesarias en el sistema para que la persona pueda ejercer en forma libre todos sus derechos" (Bustos, 2006). La concepción amplia de tal noción se ha relacionado en Chile principalmente con la función coercitiva del Estado, como respuesta a la "violencia de la calle". Tomando en cuenta que, según el Censo 2017, más del 87,8\% de la 
población vive en áreas urbanas y la mayoría de los delitos se focalizan en zonas dentro del límite urbano, se tiende a territorializar el concepto de seguridad ciudadana, identificándolo con la idea seguridad urbana. De hecho, tanto la seguridad ciudadana como la urbana se refieren a una restricción del derecho de seguridad a ciertas condiciones. En el primer caso, el derecho se restringe a una condición social: la ciudadanía. En el segundo, a una delimitación administrativa: el límite urbano.

Probablemente, una buena manera de estimar el impacto que tienen las políticas habitacionales señaladas sobre la conducta violenta de las generaciones nacidas y criadas en contextos marginados e inseguros sea visualizar territorialmente la presencia de jóvenes infractores de la ley penal. En ocasiones, la conducta delictual en niños y jóvenes resulta más bien exploratoria, de ocasión única, con lo que conviene identificar la ubicación domiciliaria de jóvenes con reincidencia delictiva. Por tanto, nuestra intención ha sido sondear a jóvenes que reiteradamente han ejercido violencia, han cometido delitos y han sido sancionados, pero que se mantienen en condición de libertad, un segmento donde aún es posible evidenciar la influencia recíproca sujeto-urbe, en el contexto de una mayor comprensión procesal y del conflicto social.

En la línea señalada, la ubicación de los domicilios de los niños y adolescentes con un comportamiento caracterizado por el delito violento y reincidente resultaría un aspecto interesante de precisar. Es quizá la situación de las sanciones de libertad asistida (en sus modalidades simple y especial, siendo ambas sanciones las más severas en medio libre del sistema penal juvenil en Chile) el marco ideal de observar, ya que, tratándose de jóvenes casi siempre reincidentes en delitos violentos, se encuentran en medio libre, con lo que las influencias recíprocas con su contexto siguen gravitando. Los jóvenes que ya se encuentran privados de libertad se mantienen en tanto en situación aislada, desde donde no son capaces de influir cotidianamente sobre su contexto social directo ni viceversa.

Por otra parte, ya que la idea es contar con una fuente adecuada de datos, conviene analizar la situación de estos jóvenes durante un tiempo suficiente y en cantidad apropiada (adecuada longitudinalidad y muestreo) y seleccionar una comuna altamente afectada por los fenómenos urbanos descritos con anterioridad, como Puente Alto, en la Región Metropolitana de Santiago de Chile.

En consecuencia, nuestra pregunta de investigación puede formularse como sigue: ¿Cómo se distribuyen geográficamente en la comuna de Puente Alto, los domicilios de jóvenes que cursan la sanción de libertad asistida (simple y especial), entre los años 2014 y 2018 ?

Para ello, se utilizarán herramientas actualizadas en georreferenciación y un análisis de datos compatible con la tarea propuesta.

\section{Georreferenciar}

En cuanto a la metodología que motiva el presente estudio, cabe destacar que la utilización de referencias geográficas al momento de analizar la problemática delictual es un método que se remonta al siglo XIX (Harries, 1999) y resulta una estrategia 
de análisis delictual profundamente masificada en la actualidad, especialmente en el área de la prevención del delito.

La forma más usual de análisis delictual a través de datos georreferenciados es delimitar o señalar el lugar de ocurrencia de los delitos, a fin de intervenir en las áreas más afectadas por estos eventos, con el objeto de disminuir la incidencia de acciones del mismo tipo en el área en cuestión. Efectivamente, a través de diferentes intervenciones, tales como el aumento de la vigilancia policial, implementación o mejoras en los sistemas de seguridad e incluso modificaciones en el diseńo urbano, este enfoque se propone disminuir la incidencia de delitos, generando espacios más seguros (Wortley \& Mazerole, 2011).

Una de las principales críticas a este modelo es que aquellos individuos propensos a delinquir simplemente no reincidirán en un lugar ya intervenido en materia de prevención situacional del delito y buscarán otros sitios menos resguardados. Como consecuencia, el foco delictual se disiparía, pero reubicándose en otros puntos, "toda vez que las causas profundas del delito no han sido intervenidas" (Guerette, 2009 , p. 1). Este fenómeno, conocido como desplazamiento delictual, deriva en controversia y se encuentra en sostenido debate. Adicionalmente, a las visiones situacionales sobre el fenómeno delictivo se les critica su simplificación y falta de fundamentos teóricos, junto con su tendencia a distraer recursos públicos, restringir las libertades personales y favorecer una sociedad excluyente, considerando algunos a este tipo de medidas como conservadoras y meramente administrativas (Wortley \& Mazerole, 2011, p. 191).

De ocurrir, el desplazamiento delictual termina -en el mejor de los casos- por aplacar la ocurrencia de nuevos delitos en áreas que cuentan con métodos de resguardo, pero aumentando su incidencia en sectores más desprotegidos o que simplemente no cuentan con recursos u organización para reforzar su seguridad. En consecuencia, dicha situación desembocaría en una prevención puramente anecdótica del delito y no en una prevención de sus causas, en sentido estricto (Figura 2).

Resulta altamente complejo medir el fenómeno de desplazamiento delictual, ya que no basta con estimar si en los alrededores de un foco delictual han ocurrido más delitos del mismo tipo, puesto que los infractores suelen desplegar un comportamiento altamente furtivo y flexible. En esta línea, Guerette (2009) ha señalado que los ofensores pueden alejarse considerablemente del anterior foco delictual y, entre otras complejidades, adoptar diferentes prácticas delictivas en función de las oportunidades que se les ofrecen (por ejemplo, transitar desde la comisión de robos por sorpresa a robos de vehículos y luego a robos en lugar no habitado). En tales circunstancias, resulta sumamente difícil calcular con exactitud tanto la efectividad de las intervenciones situacionales como el fenómeno de desplazamiento posterior a su implementación, por muy bien fundamentados que estén los argumentos a favor de las prácticas de prevención situacional.

$1 \overline{\text { Esta, así como todas las citas textuales de las referencias bibliográficas en inglés, es una traducción }}$ propia. 
FIGURA 2 | Ejemplo de desplazamiento delictual
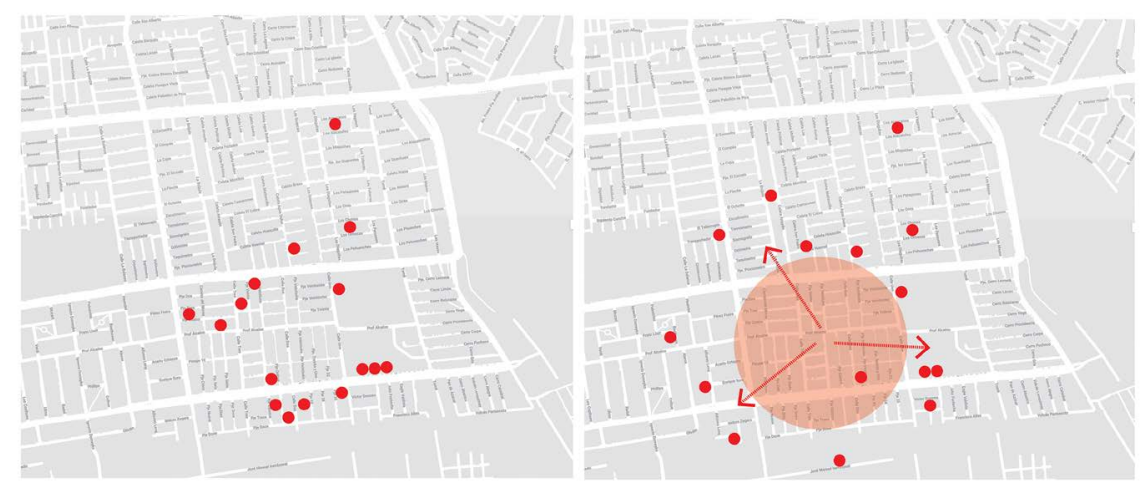

NOTA: LA INCIDENCIA DE INFRACCIONES SE DISPERSA TERRITORIALMENTE LUEGO DE LA APLICACIÓN DE MEDIDAS DE PREVENCIÓN BASADAS EN DISUADIR LA OCURRENCIA DE DELITOS, PERO LA CANTIDAD GLOBAL DE EVENTOS INFRACCIONALES ES LA MISMA QUE ANTES, AUMENTANDO EL ACCIONAR DELICTIVO EN ÁREAS MÁS DESPROTEGIDAS.

FUENTE: ELABORACIÓN PROPIA, 2019

En cuanto a la más clásica de las intervenciones situacionales y de amplísima propagación en las urbes modernas, la videovigilancia, según argumenta Galdon-Clavell (2015), a la larga ha demostrado resultados "mixtos, poco claros y, a veces, directamente divergentes (...). Como solución generalizada a problemas de seguridad ciudadana, la videovigilancia es manifiestamente deficiente" (p. 86); lo que ha redundado en "la emergencia de un sólido corpus científico que cuestiona el relato construido alrededor de la necesidad de instalar cámaras para combatir la delincuencia obliga a ir más lejos” (p. 89).

Es así como, en términos generales, plantearse una prevención estrictamente situacional del delito resulta "un contrasentido, porque si el espacio público es la ciudad, no hay que maquillar el espacio público actualmente existente, sino plantearse el diseño de un nuevo urbanismo constructor y productor de ciudad, es decir, de espacio público" (Carrión, 2008, p. 124).

Independientemente del debate al respecto, la metodología que aquí se presenta resulta diametralmente diferente al uso tradicional de los datos georreferenciados en el análisis de la conducta delictual. No se localizará geográficamente los puntos de ocurrencia de eventos delictuales, sino la ubicación de los domicilios de jóvenes infractores de ley, a fin de intentar avizorar variables de orden contextual que puedan tener relación con el origen y mantención del comportamiento delictual en jóvenes de la comuna de Puente Alto.

Asumiendo elementos de la teoría ecológica de Bronfenbrenner, que indica que el desarrollo humano se encuentra íntimamente relacionado e influido por los contextos sociales directos (Frías-Armenta, López \& Días-Méndez, 2003), es preciso indicar que las variables sociocomunitarias tienen -igualmente- especial significación al momento de intentar entender el comportamiento delictual, particularmente entre jóvenes y adolescentes. En definitiva, no es casualidad que este 
modelo teórico se encuentre acogido en las orientaciones técnicas y lineamientos para las sanciones de la Ley de Responsabilidad Penal Adolescente en Chile. ${ }^{2}$

Lamentablemente, los análisis georreferenciados de los domicilios de infractores son escasos en la literatura especializada. De esta forma, "la mayoría de las investigaciones confían en el análisis de los lugares donde los delitos ocurren, sin referencia al lugar de residencia de los infractores" (Johnson \& Summers, 2014, p. 454), mientras que aquellas investigaciones que establecen el lugar de residencia de los ofensores lo hacen casi exclusivamente a fin de establecer sus trayectos hacia el lugar de ocurrencia del evento delictivo. Se destaca entre quienes han georreferenciado el lugar de residencia de infractores a Shaw y McKay (1931, 1942), quienes "mapearon la localización residencial de jóvenes que fueron derivados a tribunales juveniles, acumulando datos durante décadas" (Messner \& Zimmerman, 2012, p. 158), y la investigación "Where Juvenile Serious Offenders Live: A Neighborhood Analysis of Wayne County, Michigan”, de Irene Ng (2010), quien analiza variables comunitarias a nivel barrial de infractores juveniles. Finalmente, en el caso de Chile, se menciona el estudio de Tamara Ortega (2014), quien analiza fenómenos de guetización en la comuna de La Pintana incorporando técnicas de información geográfica al observar la situación de infractores de ley, pero sin georreferenciar específicamente sus domicilios.

\section{Panorama preliminar}

A fin de estimar la magnitud de la problemática de libertad asistida en la comuna de Puente Alto, es necesario visualizar la situación de estas sanciones en su contexto regional y nacional. La cantidad de jóvenes condenados e ingresados a programas de Libertad Asistida Simple (PLA) y Libertad Asistida Especial (PLE), desde 2014 a 2018, a nivel nacional, es de 17.898 (8.389 pla y 9.509 PLE).

El análisis territorial de la comisión de delitos de jóvenes en Puente Alto podría iniciarse indicando que de los 794 casos PLA-PLE durante el periodo evaluado, 561 tienen como tribunal de origen el Juzgado de Garantía de Puente Alto. Ya que el tribunal donde se origina la causa penal es el que tiene jurisdicción sobre el territorio de ocurrencia del delito, significa que el 70,6\% de los jóvenes pertenecientes a programas de Libertad Asistida y residentes de Puente Alto han ingresado por un delito cometido en su propia comuna, mientras que el segundo tribunal más frecuente, el $14^{\circ}$ Juzgado de Garantía de Santiago (que solo radica las causas del 4,7\% de los casos ingresados) encausa los delitos formalizados en La Florida (comuna inmediatamente adyacente a Puente Alto). En tercer lugar, el $15^{\circ} \mathrm{Juzgado}$ de Garantía de Santiago tiene como jurisdicción La Pintana, comuna igualmente aledaña a Puente Alto, confirmándose la noción según la cual los jóvenes que infringen la ley no se alejan mucho de sus domicilios al delinquir.

2 Ley núm. 20.084, establece un sistema de responsabilidad de los adolescentes por infracciones a la Ley Penal. Última versión: 13-ago-2011. Fecha publicación: 07-dic-2005. Fecha promulgación: 28-nov-2005. En http://bcn.cl/1uvyu 
No obstante, tal como se señaló, el énfasis de esta investigación es proponer una metodología de localización de los lugares de residencia de quienes infringen la ley penal juvenil, en vez de localizar los lugares donde acontecen los hechos delictuales.

\section{Metodología (Estudio 2014-2018)}

Con posterioridad a una experiencia piloto realizada con 181 casos el año 2012, se propuso la siguiente metodología:

- Población: Jóvenes ingresados a programas de Libertad Asistida Simple y Especial (pla y Ple) de Puente Alto, entre los años 2014 y 2018.

- Muestra: 500 casos de los programas pla y ple Puente Alto, seleccionados al azar, mediante una cuota de 100 casos vigentes al ańo, entre 2014 y 2018.

Los casos excluidos corresponden a jóvenes condenados por delitos sexuales (por tratarse de una materia penal de naturaleza diferente a los fenómenos de violencia urbana que se desea analizar), nombre repetido y domicilio repetido. Se realizó una georreferenciación de domicilio en los 500 casos de la muestra, la que corresponde al 62,9\% (500/794) del total de casos ingresados a libertad asistida en Puente Alto (PLA y PLE), entre 2013 y 2017. El considerable tamaño muestral, el sistema longitudinal de cuota anual y la elección aleatoria de los sujetos brindan a la muestra una representatividad correcta respecto a la población. Los jóvenes fluctúan entre los 14 y 20 ańos (teniendo entre 14 y menos de 18 años al momento de cometer el delito) y cuentan con un nivel de escolaridad que cubre desde el primer ańo de educación primaria (primer año básico) hasta último año de secundaria (cuarto año de enseñanza media rendido) (Figura 3).

\section{FIGURA 3 | Comparación del tamaño de la muestra (500 casos) respecto a la cantidad de jóvenes de programas de libertad asistida a nivel comunal, regional y nacional entre 2014 y 2018}

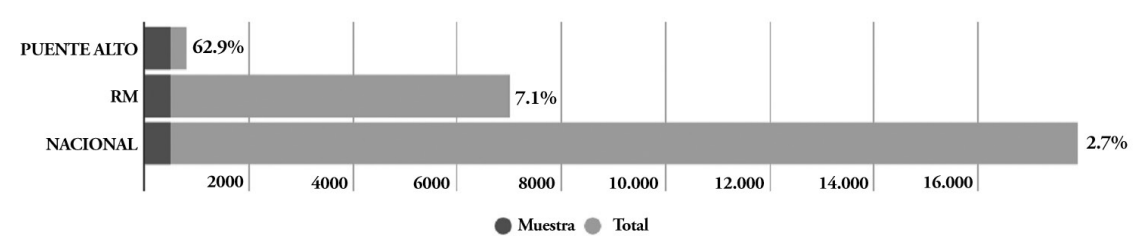

FUENTE: ELABORACIÓN PROPIA, 20 I 8

De esta forma, la ubicación domiciliaria de cada joven considerado en la muestra ha sido localizada en el plano comunal, sectorizada y asociada a una villa o población, y ha sido representada por un punto en el sistema sIG (Sistema de Información Geográfica) utilizando el software QGIS. De este modo, se han generado planos anuales y una compilación final. El objetivo que guía este despliegue de datos es iniciar de forma incipiente una descripción de la concentración y sectorización de áreas con mayor presencia de residentes sancionados por la justicia penal juvenil. La 
importancia de seleccionar la comuna de Puente Alto es que se trata de un distrito considerado emblemáticamente vinculado a niveles especialmente preocupantes de pobreza, delincuencia y estigmatización, en particular de su población juvenil, con presencia recurrente en coberturas de prensa relacionadas a estas problemáticas (Figura 4).

FIgURA 4 | Distribución espacial de la ubicación de los domicilios de 500 casos de jóvenes ingresados a programas PLA y PLE Puente Alto, considerando los seis sectores oficiales de la comuna y desagregación anual (arriba, derecha)

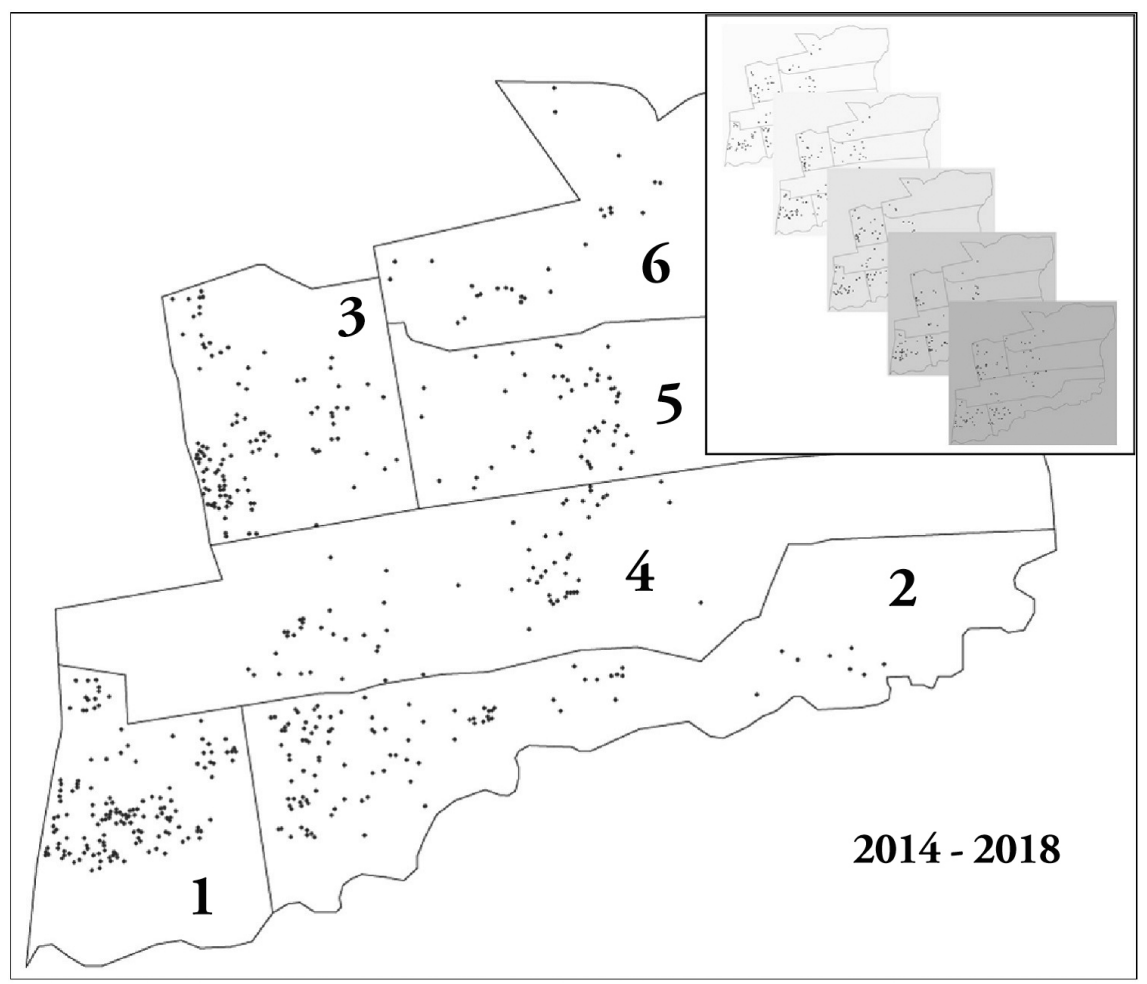

FUENTE: ELABORACIÓN PROPIA, 2018

La sectorización utilizada es la oficial establecida por la comuna de Puente Alto desde el año 2013. El sector 1 es íntegramente la zona conocida como Bajos de Mena, habitualmente asociada (a través de la prensa) a dinámicas sociales y delictivas de alta complejidad en la ciudad de Santiago.

Es posible detallar la información desagregada del número de casos por sector según se establece en la Tabla 1, cuyas cifras arrojan una distribución porcentual altamente irregular de la muestra, fijada en 100 casos por año. 
TABLA I | Cantidad y proporción de jóvenes sancionados a programas de libertad asistida en Puente Alto, por sector comunal (jóvenes vigentes por año en programas PLA y PLE)

\begin{tabular}{|c|c|c|c|c|c|c|c|}
\hline $\begin{array}{c}\text { AÑO } \\
\text { SECTOR }\end{array}$ & $\mathbf{2 0 I 4}$ & $\mathbf{2 0 I 5}$ & $\mathbf{2 0 I 6}$ & $\mathbf{2 0 I 7}$ & $\mathbf{2 0 I 8}$ & TOTAL & PORCENTAJE \\
\hline 1 & 29 & 37 & 27 & 32 & 26 & 151 & 30,20 \\
\hline 2 & 21 & 14 & 18 & 28 & 19 & 100 & 20,00 \\
\hline 3 & 21 & 22 & 25 & 13 & 28 & 109 & 21,80 \\
\hline 4 & 11 & 9 & 18 & 16 & 12 & 66 & 13,20 \\
\hline 5 & 10 & 13 & 8 & 9 & 7 & 47 & 9,40 \\
\hline 6 & 8 & 5 & 4 & 2 & 8 & 27 & 5,40 \\
\hline Total & 100 & 100 & 100 & 100 & 100 & 500 & 100 \\
\hline
\end{tabular}

FUENTE: ELABORACIÓN PROPIA, 20 I 8

\section{Problemática masificada}

Una primera aproximación al análisis sectorial permite detectar que, en ciertas zonas de la comuna de Puente Alto, la presencia de jóvenes infractores de ley se encuentra masificada: en solo la mitad de los sectores, correspondientes a los tres primeros, se concentra más del 70\% de los casos de PLA y PLE. Desde la perspectiva de las fronteras socioculturales al interior del territorio, es posible graficar la división de la comuna en dos bloques que visiblemente desempeñan un rol segregador al momento de analizar la distribución espacial de la problemática delictual juvenil en Puente Alto.

FIgURA 5 | Porcentaje de domicilios de jóvenes sancionados en la comuna de Puente Alto, considerando la avenida Ejército Libertador como eje

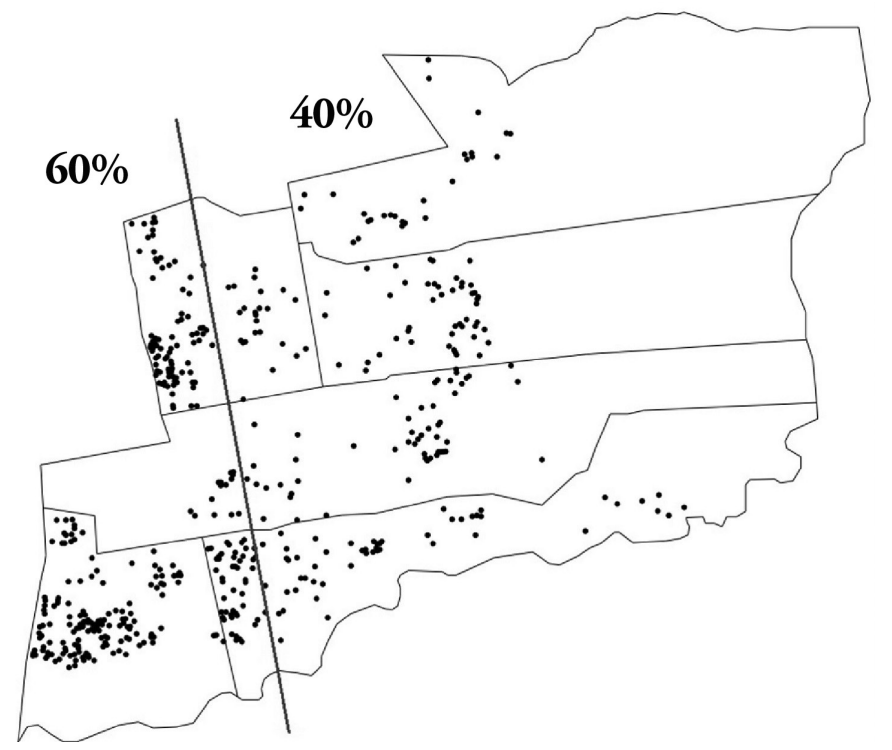

FUENTE: ELABORACIÓN PROPIA, 2018 
Tal como se observa en la Figura 5, el eje conformado por la avenida Ejército Libertador constituye un límite que divide la comuna en un sector poniente, claramente vinculado con una mayor incidencia de problemáticas sociales, incluida una significativa presencia de jóvenes infractores de ley; y un sector oriente, donde la ubicación de los jóvenes infractores no resulta tan marcadamente concentrada. En lo concreto, desde el eje Ejército Libertador al poniente se contabilizan 297 de los 500 casos referenciados, con lo que un segmento territorialmente minoritario de la comuna concentra prácticamente el $60 \%$ de los casos.

En el contexto de los sectores es además posible individualizar las poblaciones de las cuales proviene la mayor parte de los jóvenes de la muestra. De este modo, para el periodo que abarca desde 2014 a 2018 y teniendo en cuenta los 500 casos referenciados geográficamente, se ha determinado su frecuencia según la población de residencia (Tabla 2).

Tabla 2 Poblaciones de Puente Alto con mayor número de jóvenes pla y ple: cantidad de casos por población y porcentaje respecto de la comuna

\begin{tabular}{|c|l|c|}
\hline \multicolumn{2}{|c|}{ POBLACIONES } & TOTAL \\
\hline 1 & Volcán San José & 28 \\
\hline 2 & Nocedal & 19 \\
\hline 3 & San Miguel & 13 \\
\hline 4 & Marta Brunet & 12 \\
\hline 5 & Don Ramón & 12 \\
\hline 6 & El Caleuche & 12 \\
\hline 7 & Padre Hurtado & 11 \\
\hline 8 & Diego Portales & 11 \\
\hline 9 & Los Ríos & 11 \\
\hline 10 & Carol Urzúa & 10 \\
\hline 11 & Altos del Maipo & 10 \\
\hline 12 & Mamińa & 10 \\
\hline $\begin{array}{l}\text { Total } \\
\text { Porcentaje respecto del total comunal }\end{array}$ & 159 \\
\hline
\end{tabular}

FUENTE: ELABORACIÓN PROPIA, 2018

Es necesario resaltar que casi un tercio de los casos proviene de solamente 12 poblaciones. Considerando que la comuna cuenta con 627 poblaciones y villas (según página oficial de la Municipalidad de Puente Alto <http://www.mpuentealto.cl/ mapas.php>), el nivel de segregación de la problemática de jóvenes infractores de ley resulta exacerbado. En ese sentido, desde avenida Ejército Libertador al poniente podemos detectar la masificación de una pobreza "de segundo orden", donde la precariedad extrema de los campamentos de las décadas de los sesenta y setenta da paso a una pobreza "caracterizada por la posesión de una vivienda de muy bajo estándar, emplazada en espacios sin cualidades urbanas y altamente segregados en términos residenciales, educativos y laborales" (Álvarez \& Cavieres, 2016, p. 164). 
Son estos los sectores donde recae un mal renombre y cuya mala fama resulta ser una última defensa de los mismos habitantes contra la discriminación: "para este perfil de habitante es el propio territorio estigmatizado el que les proporciona las armas a través de las cuales resisten el estigma y la descalificación social de la que todos se sienten objeto" (Álvarez \& Cavieres, 2016, p. 167). Se añade a lo anterior, causando un efecto multiplicador en los sectores de masiva concentración residencial de jóvenes sancionados penalmente, tanto "la localización periférica como la condición de frontera comunal” (Lunecke, 2016, p. 116) de estas poblaciones. Tal situación aumenta la percepción de encontrarse en terreno de nadie, en lugares donde no existen mecanismos de priorización y pertenencia comunal y predominan sensaciones de permanente postergación en el emplazamiento fronterizo que se les ha asignado (el sector 1 cuenta con la avenida Santa Rosa como límite con la comuna de San Bernardo al poniente, y el sector 3 tiene la calle Acceso Sur como frontera con la comuna de La Pintana).

Independientemente de muchas variables posibles de analizar, una alta concentración de infractores de la ley en una determinada área parece propiciar en sí misma la aparición de nuevos casos, por lo que las políticas que tienen por resultado concentrar personas que infringen la ley en una densidad (por sobre la mediana) pueden lograr el incremento de nuevos infractores activos (Livingstone, Galster, Kearns \& Bannister, 2014), con un efecto recursivo y preocupante.

FIGURA 6 | Detalle del plano comunal. Se destacan mediante círculos las poblaciones con especial presencia de la problemática en estudio: de norte a sur, Don Ramón Venegas, Carol Urzúa y Diego Portales

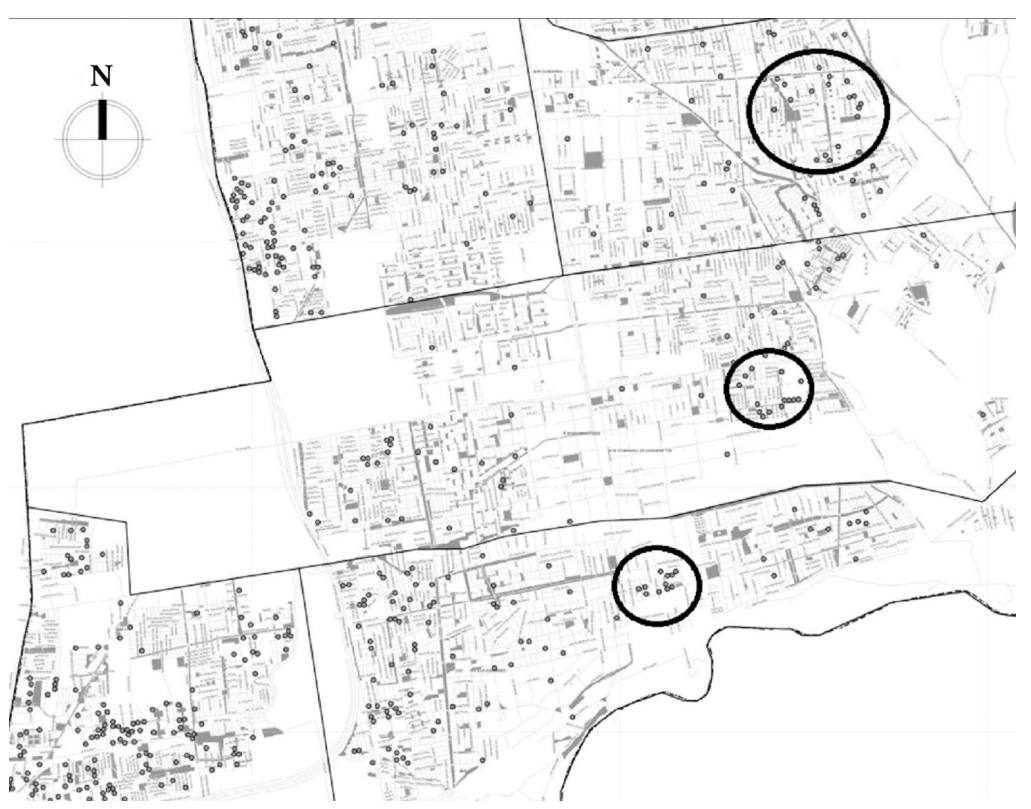

FUENTE: ELABORACIÓN PROPIA, 2018 


\section{Problemática encapsulada}

Habiendo reconocido la presencia generalizada de jóvenes infractores de la ley en algunas zonas de la comuna, es preciso igualmente destacar que existen áreas delimitadas donde la incidencia de la problemática se densifica de forma aislada. Tal es el caso de las poblaciones Don Ramón Venegas, Diego Portales y Carol Urzúa (Figura 6).

Pese a que no pertenecen a zonas con una escala de problemáticas sociales masificada y a tener un mayor acceso a servicios (colegios, centros de salud, vigilancia, conectividad, etc.), se trata de poblaciones con dinámicas internas que incluyen componentes prodelictuales (pandillas, tráfico de drogas, violencia familiar y vecinal, entre otras), quedando aisladas de su entorno directo. No se descarta en ellas, además, la acción de fenómenos de estigmatización, segregación urbana y problemas en el proceso de poblamiento; por ejemplo, conflictos ocasionados por la proveniencia de pobladores desde distintos campamentos, los que debían convivir en la misma población e iniciaron escaladas de violencia interna (Pérez, 2012, p. 47), como se ha documentado para la Población Carol Urzúa.

\section{Problemática históricamente situada}

Como tercer nivel de análisis de los datos levantados a través de una metodología georreferenciada, se puede mencionar el tramo histórico de la construcción de los proyectos inmobiliarios (Tabla 3).

TABLA 3 | Distribución de jóvenes sancionados según cantidad, por población de proveniencia, en consideración del tramo histórico de su construcción

\begin{tabular}{|c|c|c|c|c|c|c|c|c|c|}
\hline AÑO & $\begin{array}{c}\mathbf{I 9 2 2 -} \\
\mathbf{I 9 7 2}\end{array}$ & $\begin{array}{c}\mathbf{I 9 7 3 -} \\
\mathbf{I 9 8} \mathbf{I}\end{array}$ & $\begin{array}{c}\mathbf{I 9 8 2 -} \\
\mathbf{I 9 8 7}\end{array}$ & $\begin{array}{c}\mathbf{I 9 8 8 -} \\
\mathbf{I 9 9 2}\end{array}$ & $\begin{array}{c}\mathbf{I 9 9 3 -} \\
\mathbf{I 9 9 6}\end{array}$ & $\begin{array}{c}\mathbf{I 9 9 7 -} \\
\mathbf{2 0 0 0}\end{array}$ & $\begin{array}{c}\mathbf{2 0 0 I -} \\
\mathbf{2 0 0 5}\end{array}$ & $\begin{array}{c}\mathbf{2 0 0 6 -} \\
\mathbf{2 0 I O}\end{array}$ & $\begin{array}{c}\text { 20II- } \\
\mathbf{2 0 I 6}\end{array}$ \\
\hline 1 & 0 & 0 & 0 & 12 & 0 & 112 & 19 & 3 & 5 \\
\hline 2 & 9 & 8 & 19 & 19 & 4 & 15 & 19 & 6 & 1 \\
\hline 3 & 0 & 0 & 3 & 10 & 50 & 28 & 10 & 8 & 0 \\
\hline 4 & 5 & 7 & 4 & 16 & 1 & 19 & 7 & 4 & 3 \\
\hline 5 & 0 & 1 & 0 & 1 & 12 & 24 & 7 & 2 & 0 \\
\hline 6 & 0 & 0 & 0 & 2 & 16 & 6 & 2 & 1 & 0 \\
\hline Total & $\mathbf{1 4}$ & $\mathbf{1 6}$ & $\mathbf{2 6}$ & $\mathbf{6 0}$ & $\mathbf{8 3}$ & $\mathbf{2 0 4}$ & $\mathbf{6 4}$ & $\mathbf{2 4}$ & $\mathbf{9}$ \\
\hline
\end{tabular}

Casos por Sector - Tramo histórico poblaciones

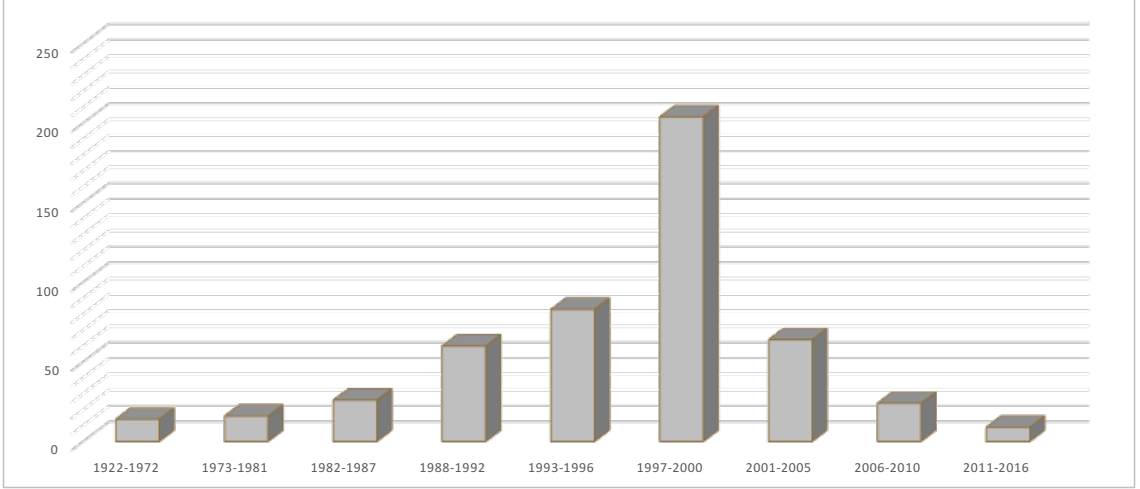

FUENTE: ELABORACIÓN PROPIA, 20 I 9 
Más del 80\% de los jóvenes infractores considerados dentro de la muestra son residentes de poblaciones construidas entre 1988 y 2005, abarcando un tramo histórico de solo 17 años. Esto permitiría descartar la hipótesis de que el comportamiento delictual de estos adolescentes ya se encontraba en conformación en el contexto de las ocupaciones de terrenos, campamentos o cualquier lugar de procedencia de sus familias antes de habitar Puente Alto, ya que se trata de jóvenes mayoritariamente nacidos y criados en estos sectores. Ello implica que el comportamiento delictual ha encontrado su lugar de gestación en el marco de estas poblaciones producidas por las políticas habitacionales desarrolladas en la transición de dictadura a democracia, extendiéndose hasta los inicios del presente siglo.

Ahondar en las características particulares de los procesos de erradicación y poblamiento desarrollados a lo largo de ese tramo histórico en particular permitiría individualizar lógicas y prácticas que es necesario evitar. A modo de ejemplo, se destaca la gran presencia de jóvenes infractores (204) residentes de poblaciones asignadas entre los años 1997 y 2000, cuyo ejemplo más tristemente célebre es el de las "Casas Copeva". Estas viviendas, desde el año 1997 y a solo meses de su entrega, presentaron problemas graves en su infraestructura, situación que terminó en la demolición de más de 700 de ellas por problemas estructurales, proceso que aún no culmina. Es quizá el tramo de años donde la calidad global de los proyectos disminuyó a niveles sin precedentes.

\section{Discusión: Proyecciones de la metodología en investigación e intervención comunitaria}

Un diagnóstico sistemático fundado en este tipo de metodologías puede tener como consecuencia el despliegue de acciones más efectivas, y dar pie a coordinaciones focalizadas y basadas en antecedentes detallados, especialmente relevantes para los programas que se encuentran en la primera línea de intervención desde la ley penal; por ejemplo, los programas de Libertad Asistida, Medidas Cautelares Ambulatorias, Servicios en Beneficio de la Comunidad, entre otros encargados centralmente de que los jóvenes sancionados penalmente disminuyan sus acciones delictuales y se reinserten en instancias formales de participación social y ejercicio de derechos.

Esta óptica de trabajo resulta importante no solo porque la intervención comunitaria se encuentra mencionada y resaltada en orientaciones técnicas y lineamientos de la ejecución de la libertad asistida (Servicio Nacional de Menores [Sename], 2012), sino porque programas de este tipo ciertamente no cuentan con toda la capacidad, recursos ni presencia en contextos locales de territorios amplios. En estas circunstancias, es indispensable la detección, priorización y coordinación con organizaciones sociales e instancias de red que se encuentran emplazadas en los diversos sectores y cuentan con líneas programáticas que permitan adoptar acciones conjuntas, en colaboración y complementariedad.

Como ya se ha mencionado, los jóvenes que ingresan a programas PLA y PLE no son casos recién iniciados en el ejercicio de prácticas delictuales (es decir, presentan una conducta infraccional reiterada y sancionada ya con anterioridad); pero, por otra parte, la conducta que han venido manteniendo no involucra privación de 
libertad. Por ende, son jóvenes infractores en los que todavía es posible y necesario intervenir justamente en esas variables sociocomunitarias que aún los afectan y que han sido decisivas en su comportamiento ilícito. En conclusión, la intervención comunitaria desde los programas PLA y PLE se presenta como última medida para incidir sobre las influencias barriales, vecinales, de redes, comunitarias y comunales.

Es precisamente este el sentido de que cursen una sanción en medio libre. Un joven privado de libertad puede cursar un régimen de entrevistas individuales, sesiones grupales, intervención en lo familiar mediante entrevistas a quienes lo visiten; puede participar en programas de nivelación escolar en contexto privativo, etcétera. Pero el desafío propio de desarrollar una sanción en medio libre es la posibilidad de que los jóvenes eviten la reincidencia mientras se mantienen inmersos en su contexto social directo, el que, si bien cuenta con componentes que los influyeron en la adopción de conductas ilícitas, también ofrece elementos que les brindan vías prosociales para desarrollar sus vidas, tal como para la mayoría de los jóvenes que residen en sectores complejos. Después de todo y sin necesidad de ninguna medición, incluso en las zonas con mayor concentración de jóvenes infractores de ley se puede asegurar que ellos no corresponden a una proporción mayoritaria de los jóvenes que residen en tales sectores.

Por otra parte, mediante un estudio georreferenciado no solo será posible seguir profundizando el análisis de zonas donde se visualice mayor problemática delictual, sino que igualmente se podrá revisar la situación de zonas blancas, es decir, aquellas inmersas en sectores complejos y que, pese a contar con hacinamiento, vulnerabilidad social, origen común en la erradicación de tomas de terreno y otras variables compartidas, no evidencian en la muestra una presencia significativa de jóvenes infractores. Es posible que estas áreas cuenten con fortalezas o factores protectores que puedan ser observados -o incluso potenciados- en poblaciones con mayor incidencia de jóvenes con conducta delictual (Figura 7).

FIGURA 7 | Ejemplo de análisis de “zonas blancas”, en los dos sectores con mayor incidencia de infracción juvenil, sectores 1 (izq.) y 3 (der.)
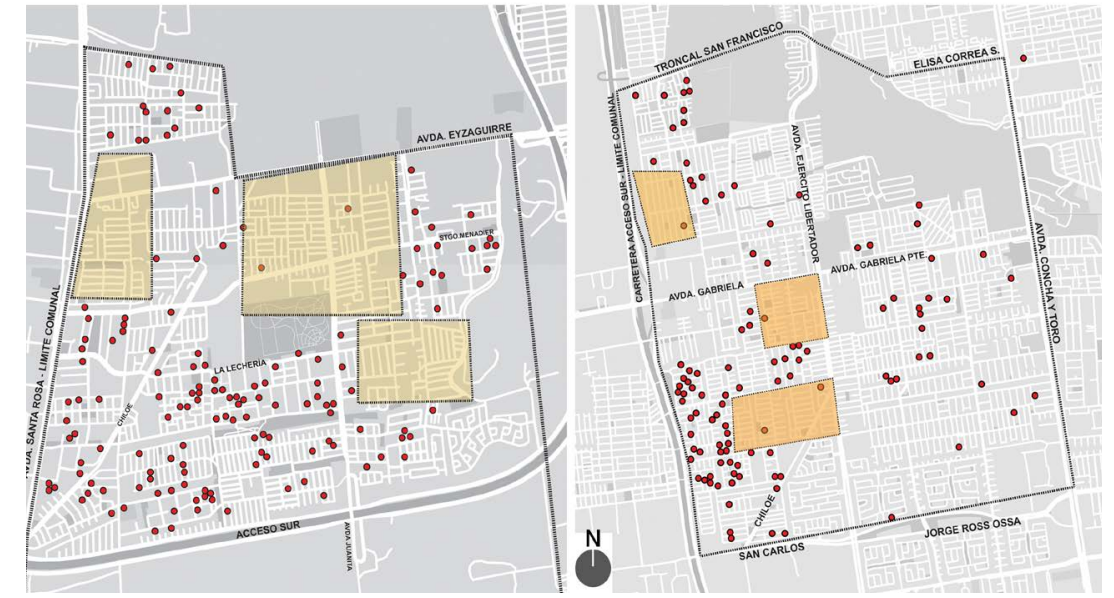

FUENTE: ELABORACIÓN PROPIA, 2019 
De este modo, en el sector 1, de poniente a oriente, las zonas blancas corresponden a las poblaciones Los Evangelistas, Estaciones Ferroviarias y Casas de San Guillermo. En el sector 3, de norte a sur, algunas zonas blancas corresponden a las poblaciones Los Robles de Puente Alto, Doña Gabriela y La Foresta III y IV. Estas áreas ofrecen la posibilidad de analizar redes, factores protectores y otros componentes sociales y urbanísticos que permitan entender por qué en ellas se da una menor presencia de juventud infractora de ley, entre otras dinámicas de preocupación.

\section{Resguardos necesarios de considerar. Confidencialidad. Cambio de narrativa}

Se ha postulado que una mejor conectividad de los territorios de destierro a los centros urbanos de intercambio podría compensar la exclusión de sus habitantes y los efectos que tal situación tiene sobre ellos. Es quizá el sentido de proponer extensiones de la Línea 4 de Metro de Santiago, prometiendo incluso una estación en pleno sector Bajos de Mena. ${ }^{3}$ Cabe destacar que las personas que han sido desterradas a las periferias, pero que necesitan "transitar por la ciudad que los expulsa", deben recrear vivencialmente las experiencias de discriminación en ese tránsito, lo que tiene por resultado "una lesión grave de los derechos de gran cantidad de personas de menores recursos a participar de los beneficios de la vida urbana, objetiva y subjetivamente" (Rodríguez, 2016, p. 75).

Por otra parte, no se debe despreciar el efecto de una posible gentrificación de los sectores modernizados o equipados urbanísticamente (Arriagada \& Rodríguez, 2003, p. 62). La valorización súbita de los terrenos beneficiados por tales inversiones se constituye en caldo de cultivo para una especulación mercantil que puede volver a imponer nuevos procesos de erradicación a las familias de menores recursos.

De esta manera, los niveles de segregación señalados y sus consecuencias deben ser afrontados de manera integral, "con medidas directas e indirectas, relativas tanto a determinantes como a efectos, y con estrategias que vinculen las dimensiones social y urbana” (Arriagada \& Rodríguez, 2003, p. 63).

Es preciso, entonces, resaltar la necesidad de estudiar con mayor profundidad los procesos de poblamiento, en particular la forma en que los movimientos de pobladores han concluido el tránsito desde la ocupación ilegal de terrenos a la obtención de la propiedad de un domicilio. Frente a este último paso el interés académico ha disminuido, lo cual ha dejado desatendidas, ajenas a una reflexión metódica, las consecuencias de la intervención habitacional que se les ha ofrecido a amplios sectores de la población urbana.

La sucesión de construcción, adecuación, demoliciones y posteriores reconstrucciones da cuenta no solo de la inoperancia administrativa de un proyecto en particular. Sus efectos sobre la población afectada van mucho más allá de eso. La extensión del sector Bajos de Mena, la cantidad de habitantes perjudicados, su estado de postergación absoluta, la reiteración de escenas y situaciones sin aparente

3 Anuncio en prensa. Por ejemplo: https://www.cooperativa.cl/noticias/pais/transportes/metro/ nueva-extension-de-la-linea-4-de-metro-unira-bajos-de-mena-con/2018-06-02/124018.html 
resolución, la sensación de atemporalidad que resulta naturalmente del seguimiento de la situación, constituyen situaciones que no dejan otra opción que evidenciar una cierta compulsión a la repetición típicamente originada en eventos traumáticos en el caso de la vida psíquica, esta vez escenificada en el marco de la urbe y en la ruptura misma del tejido social.

Las políticas urbanas señaladas, queriendo dejar atrás de la manera más acelerada posible los índices de déficit habitacional de la dictadura, han hecho pagar a los pobladores "las consecuencias de querer hacer mucho con tan poco" (Gilbert, 2004), privilegiando por sobre otros principios la mera cobertura de los beneficios, y a la vez despreciando estándares mínimos sustentables. Al contrario, la organización urbana encuentra aciertos en una toma de decisiones de largo plazo que no solo atienda la necesidad de visibilizar logros durante el tiempo que duren los cargos de poder, sino que se proponga avanzar en resultados que superen el plazo de las administraciones políticas y que integren a la comunidad.

De este modo, se valora la conveniencia de incorporar perspectivas que brinden una visión más integral del fenómeno infraccional juvenil y de las variables urbanas que potencian su aparición, mientras se resguarda la confidencialidad de la información generada sobre ciertos sectores y poblaciones, a fin de evitar una mayor estigmatización de sus habitantes. Los resguardos necesarios que se deben adoptar al momento de divulgar e intervenir sobre antecedentes como los expuestos requieren una evitación activa de la llamada "cartografía de la violencia", en el sentido que destaca Alex Tupiza (2007), enfocando la investigación en algo distinto al hegemónico discurso antidelincuencia centrado en la vigilancia. Así, se debe considerar que “cuando estos espacios 'penalizados' son o amenazan con convertirse en componentes permanentes del paisaje urbano, los discursos de denigración se amplifican y se amontonan a su alrededor, tanto 'por lo bajo', en las interacciones de la vida cotidiana, como 'desde lo alto', en el campo periodístico, político y burocrático (y también en el científico)” (Wacquant, 2007, pp. 274-275).

De este modo, tal como plantea Carrión (2008), "es necesario recuperar la geografía de la violencia, no para la estigmatización socioterritorial sino para contar con información georreferenciada que permita la toma de decisiones acorde a la realidad" (p. 119), sobre todo desde que las potentes herramientas de referenciación geográfica actuales permiten desarrollar más análisis, de mayor complejidad y en menos tiempo.

Es preciso que los análisis y medidas no se restrinjan y realmente se enfoquen en visualizar y actuar sobre las condiciones de vida, erradicación, exclusión y vulnerabilidad que han potenciado la generación, concentración desproporcionada y reproducción de situaciones de precariedad y violencia, más que en el resguardo de las áreas más habitualmente atacadas delictualmente con el fin de proteger a quienes tengan recursos para ello, solo para que las infracciones ocurran en otros sectores de la ciudad menos vigilados.

La violencia ejercida se devuelve en escalada desde la acción delictual, lo cual no aporta justificación, sino más bien un posible marco referencial comprensivo de fenómenos sociales e históricos complejos que se pueden atenuar no reiterando políticas erráticas. Sería necesario, en consecuencia, producir una actualización de 
las narrativas dirigidas al delito, a la violencia y a lo urbano que repercutan en una mejora significativa en las teorías de cambio, que orienten verdaderas mejoras en las intervenciones más que acciones exorbitantes en presupuesto y que tengan como consecuencia de largo plazo el recrudecimiento de los problemas que han prometido solucionar. Quizá, entonces, sea posible comenzar a convencernos de que los problemas habitacionales no alcanzan solución con la construcción de vivienda masiva, precaria y periférica; la inseguridad ciudadana, con drones; y la delincuencia juvenil con penas privativas de libertad, agendas cortas y paquetes de medidas.

Desde otra narrativa y teoría del cambio, podríamos pensar que quizá las problemáticas analizadas se deban, en primer lugar, al desconocimiento absoluto del posible aporte que el poblamiento popular pudo producir en la construcción de ciudad y ciudadanía, donde las masas de pobladores han sido objeto y no parte del proceso de habitar y arraigar en la ciudad. Se observa una desatención sistemática a posibles mecanismos de protección de los ciudadanos ante contextos de crecimiento acelerado en el proceso de urbanización, donde la ciudad realmente mantenga rasgos que reflejen ser un ámbito de realización de los derechos humanos, y se constituya en un espacio donde precisamente los ciudadanos en situación vulnerable sean parte y objeto de medidas especiales, desde una afirmación positiva y reconocimiento. Es imprescindible la validación de las organizaciones y movimientos sociales como interlocutores en los procesos de planificación urbana, de manera que ya no sean objeto de las políticas, sino sujetos activos y empoderados en la resolución de sus propios conflictos y en la satisfacción de sus necesidades. Lo anterior amerita que el diseño urbano acoja plataformas asociativas de amplia participación.

- Desde una amplia definición del derecho a la vivienda, podemos entenderlo como el "derecho de toda persona a poseer un hogar que le garantice intimidad y seguridad, así como a su familia, en un contexto de integración espacial y urbana, acceso adecuado a equipamiento público y privado y de disfrute pleno y equitativo de la Ciudad y sus Bienes Comunes, que permita la interacción social, y un habitar pacífico, digno y lúdico, garantizado por la co-actividad y la co-gestión de quienes producen socialmente el espacio, sin discriminación” (Villas, 2018, p. 207).

- A pesar de que Chile ha ratificado todos los tratados internacionales y regionales más relevantes en temas de derechos humanos, y en específico los atingentes al derecho a una vivienda digna, este aún no ha sido reconocido de manera vinculante por la legislación chilena. Aunque la Constitución vigente incluye de manera indirecta, en el artículo 5.2, la promoción de los derechos garantizados por la misma Constitución y por los tratados internacionales vigentes, estos aún no son exigibles ante ningún tribunal.

- No obstante lo anterior, el Estado, en las últimas décadas, ha promovido ciertos programas habitacionales en un contexto de revisión de la política subsidiaria vigente, buscando mitigar en alguna medida la alta segregación social y baja calidad de las viviendas. Así, programas como el de Renovación Urbana y Desarrollo Prioritario (1990), y el Programa Privado de Vivienda Básica de 
Libre Elección (1994), entre otros, pretenden romper con la lógica de la localización periférica de la vivienda social.

El acceso y movimiento en la ciudad deben estar enmarcados en un plan de desplazamiento urbano justo, que considere en costo, distancia y tiempo la situación específica de exclusión y vulnerabilidad de grandes grupos humanos depositados en las periferias.

La seguridad urbana, como atributo del espacio público, sería producto de la integración, del ejercicio de derechos, de una convivencia pacífica no excluyente, donde el usufructo de la ciudad sea patrimonio de todos y donde confluyan la diversidad, la memoria y la identidad cultural.

Complementariamente, los sistemas de administración de la justicia deberían desplegar acciones específicas en atención a los grupos vulnerables, donde la seguridad pública no se restrinja a la vigilancia, persecución y penalización de conductas particulares, sino que apunte a una convivencia pacífica facilitada por mecanismos de conciliación, transacción, mediación y arbitraje, capaces de incluir un modelo restaurativo en justicia, especialmente en la esfera penal juvenil.

Varios de los principios anteriormente descritos se encuentran concordados en la Carta Mundial por el Derecho a la Ciudad (Foro Social de las Américas, 2012), apoyada por instancias como Unesco y onU Hábitat, formulación que despliega fundamentos mínimos que contrapesen -en algo- un mercado inmobiliario y de terrenos que ha orquestado consecuencias muchas veces nefastas, y muchas de ellas aún por ser explicadas.

\section{Agradecimientos}

Los autores desean agradecer la importante contribución en este estudio de la psicóloga Simone Lahr, Universidad de Maastricht, Holanda.

\section{Referencias bibliográficas}

Álvarez, A. M. \& Cavieres, H. (2016). El Castillo: territorio, sociedad y subjetividades dela espera. EURE, 42(125), 155-174. http:// doi.org/10.4067/S0250-71612016000100007

Angelcos, N. \& Pérez, M. (2017). De la "desaparición" a la reemergencia: Continuidades y rupturas del movimiento de pobladores en Chile. Latin American Research Review, 52(1), 94-107. http://doi.org/10.25222/larr.39

Arriagada, C. \& Morales, N. (2006). Ciudad y seguridad ciudadana en Chile: Revisión del rol de la segregación sobre la exposición al delito en grandes urbes. EURE, 32(97), 37-48. http://dx.doi.org/10.4067/S0250-71612006000300003

Arriagada, C. \& Rodríguez, J. (2003). Segregación residencial en áreas metropolitanas de América Latina: magnitud, características, evolución e implicaciones de politica. Serie Población y desarrollo 47 [LC/L.1997-P]. Santiago de Chile: Comisión Económica para América Latina y el Caribe (CEPAL). https://repositorio.cepal.org/bitstream/ handle/11362/7189/1/S0310709_es.pdf 
Bustos, J. (2006). Seguridad ciudadana y seguridad jurídica. Nuevo foro penal, 12(70), 159167. http://publicaciones.eafit.edu.co/index.php/nuevo-foro-penal/article/view/3783

Carrión, F. (2008). Violencia urbana: un asunto de ciudad. EURE, 34(103), 111-130. http:// dx.doi.org/10.4067/S0250-71612008000300006

Del Romero, L. (2018). Cartografías de la desigualdad: Una década de conflictos de vivienda y nuevas residencias en Santiago de Chile. Análisis del conflicto de la Maestranza de San Eugenio. EURE, 44(132), 47-66. http://dx.doi.org/10.4067/s0250-716120 18000200047

Ducci, M. E. (1997). Chile: el lado oscuro de una política de vivienda exitosa. EURE, 23(69), 99-115. http://www7.uc.cl/sw_educ/cyv/pdf/chile.pdf

Foro Social de las Américas (2012). Carta Mundial por el Derecho a la Ciudad. Paz y Conflictos, 5, 184-196. http://revistaseug.ugr.es/index.php/revpaz/article/view/473/555

Frías-Armenta, M., López, A. \& Días-Méndez, S. (2003). Predictores de la conducta antisocial juvenil. Un modelo ecológico. Revista Estudios de Psicología, 8(1), 15-24. https://doi. org/10.1590/S1413-294X2003000100003

Galdon-Clavell, G. (2015). Si la videovigilancia es la respuesta, ¿̨uál era la pregunta? Cámaras, seguridad y políticas urbanas. EURE, 41(123), 81-101. http://doi.org/10.4067/ S0250-71612015000300004

Gilbert, A. (2004). Helping the poor through housing subsidies: lessons from Chile, Colombia and South Africa. Habitat International, 28(1), 13-40. https://doi.org/10.1016/ S0197-3975(02)00070-X

Guerette, R. (2009). Analyzing crime displacement and diffusion. Washington, DC: U.s. Department of Justice. https://popcenter.asu.edu/sites/default/files/tools/pdfs/ displacement.pdf

Harries, K. (1999). Mapping crime. Principle and practice. Washington, DC: U.s. Department of Justice; Office of Justice Programs. https://www.ncjrs.gov/pdffiles1/nij/178919.pdf

Johnson, S. D. \& Summers, L. (2014). Testing ecological theories of offender spatial decision making using a discrete choice model. Crime \& Delinquency, 61(3), 454-480. https:// doi.org/10.1177\%2F0011128714540276

Livingstone, M., Galster, G., Kearns, A. \& Bannister, J. (2014). Criminal neighbourhoods: does the density of prior offenders in an area encourage others to commit crime? Environment and Planning, 46(10), 2469-2488. https://doi.org/10.1068/a140180p

Lunecke, A. (2016). Inseguridad ciudadana y diferenciación social en el nivel microbarrial: el caso del sector Santo Tomás, Santiago de Chile. EURE, 42(125), 109-129. http:// dx.doi.org/10.4067/S0250-71612016000100005

Manzano, L. (2009). Violencia en barrios criticos: Explicaciones teóricas y estrategias de intervención basadas en el papel de la comunidad. Santiago, Chile: RIL.

Messner, S. \& Zimmerman, G. (2012). Community-level influences on crime and offending. En B. Welsh \& D. Farrington (Eds.), The Oxford Handbook of Crime Prevention (pp. 155-172). Oxford, RU: Oxford University Press.

$\mathrm{Ng}$, I. (2010). Where juvenile serious offenders live: a neighborhood analysis of Wayne County, Michigan. Journal of Criminal Justice, 38(2), 207-215. https://doi.org/10.1016/j. jcrimjus.2010.02.002 
Ortega, T. (2014). Criminalización y concentración de la pobreza urbana en barrios segregados. Síntomas de guetización en La Pintana, Santiago de Chile. EURE, 40(120), 241-263. http://dx.doi.org/10.4067/S0250-71612014000200012

Oxhorn, P. (2004). La paradoja del gobierno autoritario: Organización de los sectores populares en los ochenta y promesa de inclusión. Política, 43, 57-83. https://revistas.uchile.cl/ index.php/RP/article/view/55743

Pérez, A. (2012). Identidad social de los habitantes de la Población Carol Urzúa perteneciente a la comuna de Puente Alto. Tesis de maestría, Universidad de Chile, Santiago.

Rodríguez, P. (2016). El debilitamiento de lo urbano en Santiago, Chile. EURE, 42(125), 6179. http://dx.doi.org/10.4067/S0250-71612016000100003

Sabatini, F., Cáceres, G. \& Cerda, J. (2001). Segregación residencial en las principales ciudades chilenas: tendencias de las tres últimas décadas y posibles cursos de acción. EURE, 27(82), 21-42. http://dx.doi.org/10.4067/S0250-71612001008200002

Salazar, G. (2012). Movimientos sociales en Chile. Santiago, Chile: Uqbar.

Saraví, G. (2004). Segregación urbana y espacio público: los jóvenes en enclaves de pobreza estructural. Revista de la Cepal, 83, 33-48. https://repositorio.cepal.org/ handle/11362/10962

Servicio Nacional de Menores, Chile. (2012). Orientaciones Técnicas para la Intervención. Libertad Asistida Especial. http://www.sename.cl/wsename/otros/OT_03-07-2014/ Orientaciones\%20T\%C3\%A9cnicas\%20Libertad\%20Asistida\%20Especial\%202012. pdf

Shaw, C. \& McKay, H. (1931). Social factors in delinquency. Chicago, IL: University of Chicago Press.

Shaw, C. \& McKay, H. (1942). Juvenile delinquency and urban areas. Chicago, IL: University of Chicago Press.

Sierralta, C. (2008). Efectos de la segregación residencial socioeconómica en los jóvenes de extracción popular en Santiago de Chile (1992-2002). Tesis de maestría, Pontificia Universidad Católica de Chile, Santiago.

Tupiza, A. (2007). La cartografía delictual y la seguridad ciudadana. Quito: Flacso-Ecuador.

Villas, D. (2018). Derecho a la vivienda, derecho a la ciudad y producción social del hábitat. Tesis de pregrado, Universidad de Chile, Santiago. http://repositorio.uchile.cl/ handle/2250/152385

Wacquant, L. (2007). Los condenados de la ciudad: Gueto, periferias y Estado. Buenos Aires: Siglo XXI.

Wortley, R. \& Mazerole, L. (2011). Environmental criminology and crime analysis. Nueva York: Routledge. 